\title{
COMPARISON OF THE RESULTS OF SINGLE LEVEL CERVICAL DISC ARTHROPLASTY VERSUS ANTERIOR CERVICAL DISCECTOMY IN SHORT TO MID-TERM FOLLOW-UP
}

\author{
(1) Necati Üçler ${ }^{1}$, (1) Hakan Çakın², (1) Ebru Güzel³, (1) Aslan Güzel ${ }^{4}$ \\ ${ }^{1}$ Adıyaman University Training and Research Hospital, Clinic of Neurosurgery, Adıyaman, Turkey \\ ${ }^{2}$ Akdeniz University Faculty of Medicine, Department of Neurosurgery, Antalya, Turkey \\ ${ }^{3}$ Gaziantep Medical Park Hospital, Clinic of Radiology, Gaziantep, Turkey \\ ${ }^{4}$ Gaziantep Medical Park Hospital, Clinic of Neurosurgery, Gaziantep, Turkey
}

\begin{abstract}
Objective: The aim of this retrospective study is to compare results of single-level cervical disc arthroplasty (CDA) versus anterior cervical discectomy and fusion (ACDF) in two different centers with short to mid-term follow-up.

Materials and Methods: Both surgical techniques were applied by 2 different surgeons and in 2 different centers. While ACDF was performed by the surgeon in one clinic, CDA was performed by another surgeon in another clinic, in order to avoid surgical bias, and another surgeon from a different clinic performed a statistical evaluation. Modified Japanese Orthopedic Association score (mJOA), Modic changes (MC), neck disability index (NDI) and visual analogue scale (VAS), perioperative dysphagia, and the time to return work scores of the patients were evaluated in the study.

Results: Seventy-one patients were included in the study. Thirty-two of them underwent ACDF with a median follow-up period of 15 months, and 39 underwent CDA with a median follow-up period of 16 months. The median preoperative lost workdays were statistically significantly higher in the ACDF group compared to the CDA group $(p=0.009)$. Patients in the CDA group had statistically significantly more pain intensity $(p<0.001)$ and lower $\mathrm{mJOA}$ score before the surgery $(p<0.001)$. Neck disability was significantly more severe in the ACDF group compared to the CDA group according to the preoperative NDI score $(p=0.014)$. Improvements in VAS and mJOA scores were significantly better in the CDA group compared to the ACDF group ( $p=0.004$ and $p<0.001$, respectively). The type 1 and type 2 MC were more frequent in the ACDF group than the CDA group, preoperatively. There was a statistically significant difference in preoperative MC among the groups $(p=0.010)$.

Conclusion: In our study, both surgical techniques achieved satisfactory results. However, due to the short-term nature of the study, MC could not be evaluated and a definite opinion on this matter could not be reached.

Keywords: Modic changes, cervical disc, outcome, arthroplasty, discectomy
\end{abstract}

\section{INTRODUCTION}

Surgery has an important place in the treatment of degenerative cervical conditions that do not respond to medical therapy and cause progressive neurological dysfunction. Cervical disc arthroplasty (CDA) has been developed as a safe and segmental motion-preserving method against anterior cervical discectomy and fusion (ACDF) method in the surgical treatment of cervical radiculopathy and myelopathy caused by spondylosis and acute disc herniation ${ }^{(1)}$. Although ACDF is accepted as the standard treatment for cervical radiculopathy and myelopathy, there are reservations regarding ACDF since increased motion and intradiscal pressure in the fusion of adjacent levels causes symptomatic adjacent-segment disc degeneration ${ }^{(2,3)}$. This problem of the ACDF system has led to the development of different CDA systems.

ACDF, which was first defined by Smith-Robinson and Cloward in the 1950s, is an important method in the treatment of cervical degenerative disease ${ }^{(4)}$. However, in the long term, this method can cause adjacent segment degeneration or instability. CDA has been developed as an alternative to ACDF because it can provide intervertebral disc height and segment activity, and has become a non-fusion method. The increase in adjacent segment degeneration caused by ACDF is reduced by CDA, which has been evaluated as "good" in clinical studies(5,6). There is limited information in the literature regarding the comparison of "short to mid-term" outcomes of these two methods, which are frequently used in cervical pathologies. The 
turkishspine

aim of this study is to compare clinically important outcomes of single-level CDA versus ACDF at two different clinics in short to mid-term follow-up.

\section{MATERIALS AND METHODS}

Ethical approval was obtained from Akdeniz University Faculty of Medicine Clinical Research Ethic Committee (approval no: KAEK-718, date: 13.10.2021).

In this retrospective study, the surgeries performed in two different neurosurgery centers between December 2015 and December 2019 were compared. Patients had C3-7 single-level disc disorder. Before surgery, all patients had no response to medical and physical therapy and rehabilitation treatments. The surgical indications were evaluated according to soft disc herniation, spondylotic disc, the occurence of cervical spinal cord myelopathy or hyperintense signal and "the anterior cervical surgical approach" was used in all patients. Polyetheretherketone cage or disc prosthesis was applied for fusion. Inclusion criteria were as follows: (1) subjects were 18 years old or greater and underwent surgical treatment for symptomatic cervical disc disease; (2) the intervention was ACDF and "mobile" CDA; (3) the study reported at least one valid outcome which included NDI, neck and arm pain assessments, neurological success, overall success, radiographic evaluation, complications, and reoperation; (4) patients were excluded if they had a multi-level disc disease, acute spinal fracture, infection, tumor, osteoporosis, rheumatoid arthritis, severe spondylosis, or more than one vertebral level requiring treatment.

Modified Japanese Orthopedic Association score (mJOA), Modic changes (MC), neck disability index (NDI) and visual analogue scale (VAS), perioperative dysphagia, the time to return work scores of the patients were evaluated in the study. Postoperative surgical results were analyzed according to Odom et al. ${ }^{(7)}$ criteria.

Radiological evaluations were made with plain and functional radiographs before and after the operations. These evaluations were used for the surgical choice and the follow-ups. Measurements were taken from various perspectives: cervical lordosis in the neutral position and in flexion and extension cervical lordosis was measured between $\mathrm{C} 2$ and $\mathrm{C} 7$ according to $\mathrm{Cobb}^{(8)}$. In the follow-up, new formation in anterior and posterior of vertebral corpus and collapse in operation spacing $(>2 \mathrm{~mm})^{(9)}$ were evaluated. In flexion-extension position, $>2^{\circ}$ movement in lateral radiography was accepted as pseudoarthrosis ${ }^{(10,11)}$.

For preoperative and postoperative clinical evaluations NDI and VAS, mJOA, preoperative $\mathrm{MC}$, and $\mathrm{MC}$ at the $8^{\text {th }}$ month were used.

Both surgical techniques were applied by two different surgeons and different centers. While ACDF was performed by surgeon $A$ in one center, CDA was performed by surgeon $B$ in another center, in order to avoid surgical bias, another surgeon $C$ from a different center performed a statistical evaluation.

\section{Statistical Analysis}

Statistical analyses were performed using SPSS version 20 statistical package program (IBM Corp. in Armonk, NY). ShapiroWilk and Kolmogorov-Smirnov tests were used to evaluate the distribution of the numeric variables. Descriptive data were presented as mean \pm standard deviation and median with interquartile range for numerical variables, whereas frequency and percentage were used for categorical variables. Pearson chi-square test and Fisher's exact test were used to compare categorical variables, and the Mann-Whitney $U$ test was used to compare the non-normally distributed numeric data, between two study groups. $\mathrm{P}<0.05$ was considered statistically significant.

\section{RESULTS}

This retrospective comparative study was carried out with patients who underwent ACDF and CDA between December 2015 and December 2019. Demographics and preoperative findings of the patients were shown in Table 1. Throughout this period, 71 patients were included in the study. Thirty-two of them underwent ACDF with a median follow-up period of 15 months, and 39 underwent CDA with a median followup period of 16 months. The female to male ratio, age, and prevalence of preoperative dysphagia were similar among the groups. There was a statistically significant difference in the distribution of the level-of-disc disorder between groups $(p=0.007)$, and $\mathrm{C} 4-\mathrm{C} 5$ level-of-disc disorder was more prevalent in the ACDF group compared to the CDA group; however, the most prevalent disc disorder was at the C5-C6 level in both two groups. Radiculopathy and myelopathy were significantly more prevalent in the CDA group, and radiculomyelopathy and neck pain were more prevalent in the ACDF group $(p=0006)$.

The median preoperative lost workdays were statistically significantly higher in the ACDF group compared to the CDA group $(p=0.009)$. Patients in the CDA group had statistically significantly more pain intensity $(p<0.001)$ and lower mJOA score before the surgery $(p<0.001)$. Neck disability was significantly more severe in the ACDF group compared to the CDA group according to the preoperative NDI score $(p=0.014)$ (Table 1).

Improvements in VAS and mJOA scores were significantly better in the CDA group compared to the ACDF group ( $p=0.004$ and $p<0.001$, respectively), notwithstanding the differences in preoperative and postoperative NDI scores of the groups were statistically similar (Table 2 and Figure 1).

The type 1 and type 2 MC were more frequent in the ACDF group than the CDA group, preoperatively. There was a statistically significant difference in preoperative MC among the groups $(p=0.010)$; however, this difference was diminished in favor of the ACDF group at the postoperative $8^{\text {th }}$ month (Table 3 ).

Postoperative dysphonia as a complication of the surgery occurred only in one patient who underwent ACDF. Besides, there was no dysphonic patient in the CDA group, postoperatively, 
and this difference was not statistically significant. We found that the CDA method was more successful in clinical outcomes according to the postoperative $3^{\text {rd }}$ month Odom criteria $(\mathrm{p}=0.002)$ (Table 4).

The time to return to work, which is the social indicator of surgical success, was significantly longer in the CDA group with a median of 20 days than the ACDF group with a median of 15 days $(p=0.004)$ (Table 5 and Figure 2).

\section{DISCUSSION}

Dysphonia and dysphagia rates, which could be a clue to the evaluation of our surgical technique, were compatible with the literature ${ }^{(12,13)}$. However, in some studies, dysphagia was found to be more common in ACDF groups due to excessive retraction ${ }^{(14)}$. In our study, there was no statistically significant difference between the two groups.

There are two surgical methods in the treatment of cervical disc disease: ACDF and CDA. CDA emerged after ACDF claiming to preserve movement and prevent adjacent segment disease. The superiority of either method over the other has not been demonstrated clearly. The most important disadvantage of ACFD is that the motion segment is lost and fused. Therefore, some authors emphasized that adjacent segment disease is more common in patients treated with $\mathrm{ACFD}^{(14)}$. It has been suggested that CDA provides a physiological mechanism since it maintains the disc level, provides better spinal dynamism and reflects less stress on the disc distance ${ }^{(15)}$.

Table 1. Demographics and preoperative findings of the patients

\begin{tabular}{|c|c|c|c|}
\hline Characteristics $(n=65)$ & ACDF $(n=32)$ & $\operatorname{CDA}(n=39)$ & p-value \\
\hline Sex, $(F / M)$ & $13 / 19$ & $19 / 20$ & $0.495^{*}$ \\
\hline Age (year), median (IQR) & $46.0(42.0-49.5)$ & $46.0(40.0-52.0)$ & $0.871^{* *}$ \\
\hline Disc level, n (\%) & & & $0.007^{* * *}$ \\
\hline $\mathrm{C} 3-\mathrm{C} 4$ & $3(9.4)$ & $0(0.0)$ & \\
\hline $\mathrm{C} 4-\mathrm{C} 5$ & $19(25.0)$ & $2(5.1)$ & \\
\hline $\mathrm{C} 5-\mathrm{C} 6$ & $19(40.6)$ & $28(71.8)$ & \\
\hline $\mathrm{C} 6-\mathrm{C} 7$ & 19 (21.9) & $9(23.1)$ & \\
\hline C7-T1 & $19(3.1)$ & $0(0.0)$ & \\
\hline Indication for surgery, n (\%) & & & $0.006^{* * *}$ \\
\hline Radiculopathy & $17(53.1)$ & $30(76.9)$ & \\
\hline Myelopathy & $5(15.6)$ & $8(20.5)$ & \\
\hline Radiculomyelopathy & $6(18.8)$ & $0(0.0)$ & \\
\hline Neck pain & $4(12.5)$ & $1(2.6)$ & \\
\hline Preoperative lost work days, median (IQR) & $9.0(7.0-30.0)$ & $6.0(4.0-15.0)$ & $0.009^{* *}$ \\
\hline Preoperative VAS score, median (IQR) & $7.0(6.0-7.8)$ & $8.0(7.0-8.0)$ & $<0.001^{* *}$ \\
\hline Preoperative mJOA score, median (IQR) & $13.0(11.3-14.0)$ & $16.0(16.0-117.0)$ & $<0.001^{* *}$ \\
\hline Preoperative NDI score, median (IQR) & $32.5(20.0-40.0)$ & $22.0(19.0-31.0)$ & $0.014^{* *}$ \\
\hline Follow-up period (month), median (IQR) & $15.0(13.0-18.0)$ & $16.0(12.0-19.0)$ & $0.535^{* *}$ \\
\hline
\end{tabular}
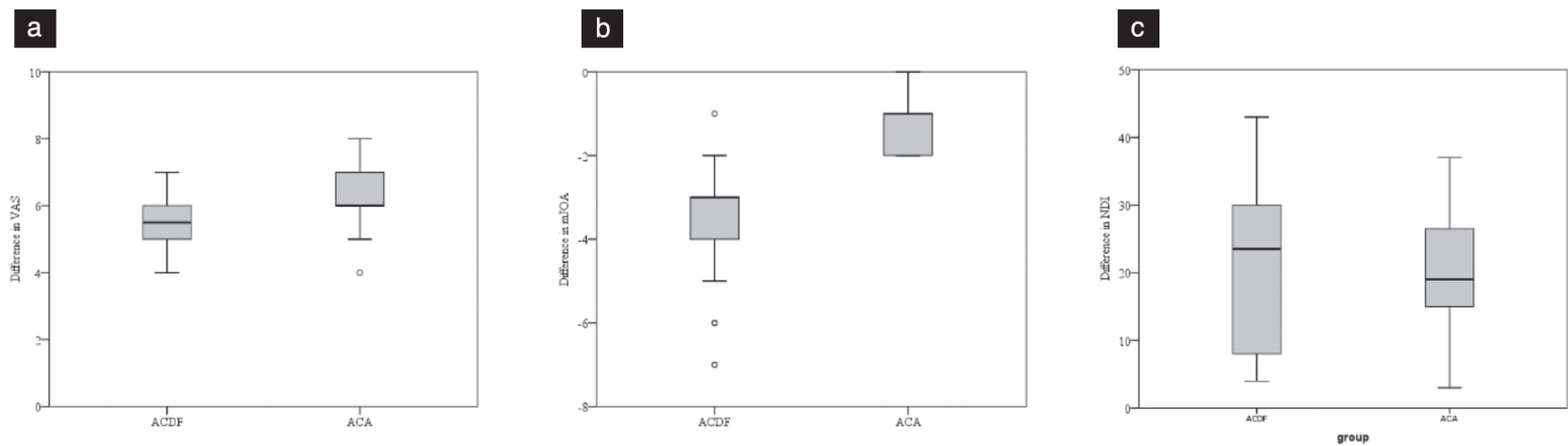

Figure 1. Boxplots of the difference in preoperative and postoperative (a) VAS, (b) mJOA and (c) NDI scores VAS: Visual analogue score, mJOA: Modified Japanese Orthopedic Association score, NDI: Neck disability index 
turkishspine

In a meta-analysis, no difference was found between the two surgical methods in NDI and pain scores ${ }^{(16)}$. The results of our study were parallel to studies comparing the short-term results of CDA with $\mathrm{ACDF}^{(14)}$. However, VAS and mJOA scores were relatively better than the CDA group, while NDI scores were the same.

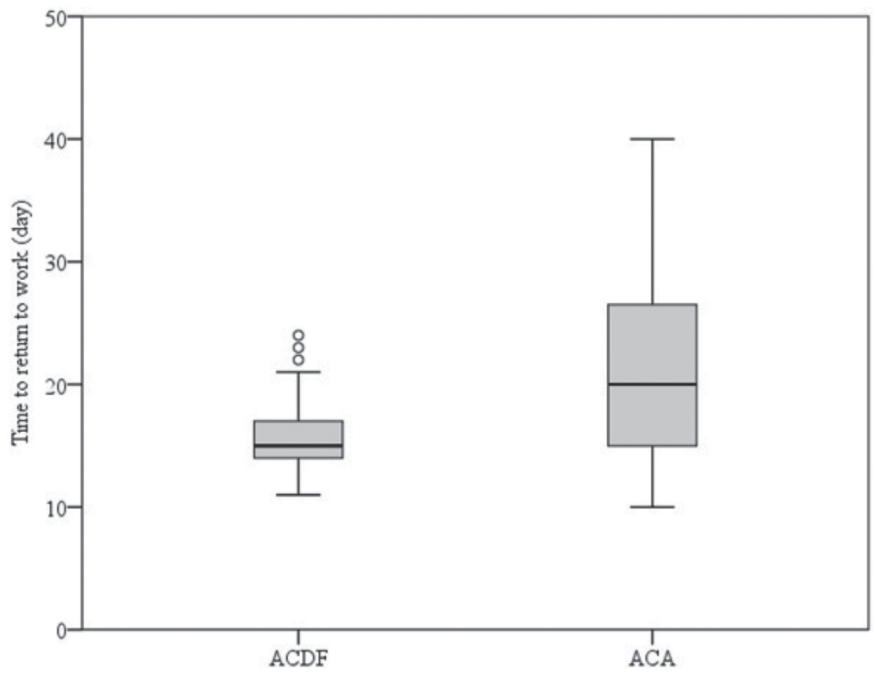

Figure 2. Boxplots of the time to return to work in days among the study groups

ACDF: Anterior cervical discectomy and fusion
Cervical degenerative disease is a chronic active process that can manifest itself with radiculopathy and myelopathy ${ }^{(17)}$. Since it is the most active cervical region, cervical degeneration is most commonly seen at $\mathrm{C} 5 / 6^{(18)}$. Repeated loads or neck activities cause mechanical strain on the endplate and disc regions of the cervical spine. $M C$, degenerative changes to vertebral endplate and subchondral bone marrow that can be detected by magnetic resonance imaging (MRI), are strongly associated with degenerative disc disease ${ }^{(19)}$. Therefore, MC are also seen most frequently at $\mathrm{C} 5 / 6^{(20)}$.

In this study, we also evaluated $M C$ between the two surgical methods. In this study, the MC in our preoperative ACDF patient group (10/32, 31.25\%) were greater than the CDA group (3/39, $7 \%)$. However, $\mathrm{MC}$ in the CDA group increased in postoperative follow-up (9/39, 23\%), and the difference with the ACDF group $(16 / 32,50 \%)$ lost its significance.

Cervical MC was first described by Peterson et al. ${ }^{(21)}$ as the signal change in the vertebral endplate and subchondral bone marrow in MRI. In subsequent studies, the incidence of $M C$ in the cervical region was reported to be between $3-40 \%(22,23)$. Peterson et al. ${ }^{(21)}$ found that the most common change was type 1 ; however, in many studies, type $2 \mathrm{MC}$ was found to be the most frequent change ${ }^{(23)}$.

$M C$ are considered to be chronic inflammatory changes(22). Inflammatory factors such as interleukin, prostaglandin E2, PGP 9.5 , and tumour necrosis factor have been found in $M C^{(24)}$. The

Table 2. Difference in preoperative and postoperative VAS, mJOA and NDI scores

\begin{tabular}{|c|c|c|c|c|}
\hline Scale & & $\operatorname{ACDF}(n=32)$ & $\operatorname{CDA}(n=39)$ & $p^{*}$ \\
\hline \multirow{2}{*}{ Difference in VAS } & Mean \pm SD & $5.5 \pm 0.9$ & $6.3 \pm 2.93$ & 0.004 \\
\hline & Median (IQR) & $5.5(5.0-6.0)$ & $6.0(6.0-7.0)$ & \\
\hline Difference in mJOA & Median (IQR) & $-3.0(-4.0 /-3.0)$ & $-1.0(-2.0 /-1.0)$ & \\
\hline Difference in NDI & Mean \pm SD & $21.3 \pm 12.3$ & $20.4 \pm 7.4$ & 0.619 \\
\hline
\end{tabular}

* Mann-Whitney $U$ test was used.

SD: Standard deviation, IQR: Interquartile range, VAS: Visual analogue score, mJOA: Modified Japanese Orthopedic Association score, NDI: Neck disability index, ACDF: Anterior cervical discectomy and fusion, CDA: Cervical disc arthroplasty

Table 3. Comparison of preoperative and postoperative Modic changes among study groups

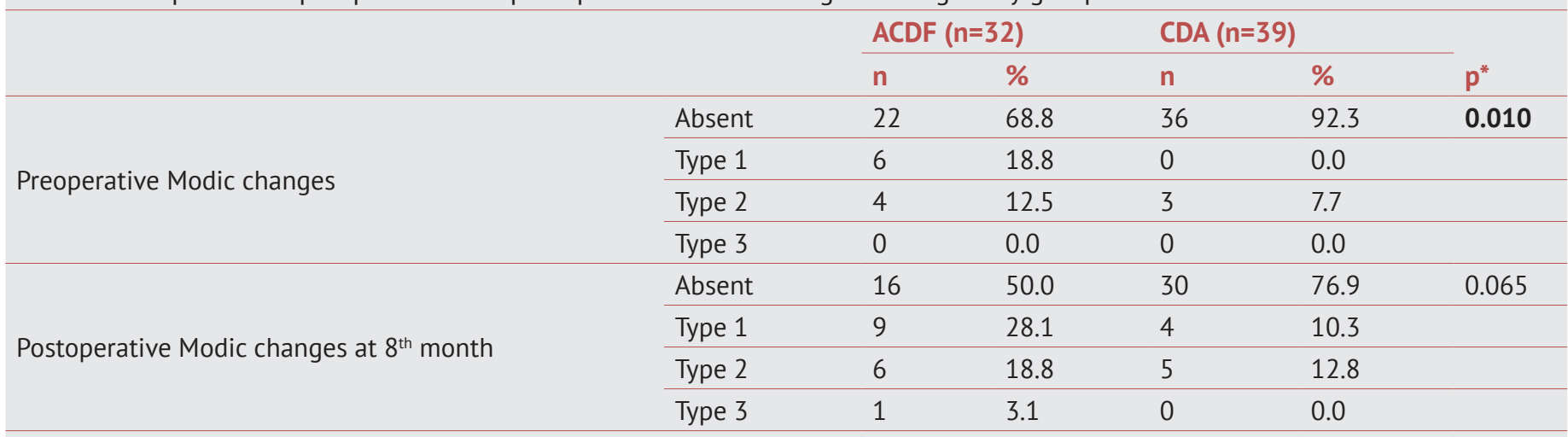

${ }^{*}$ Fisher's exact test was used

ACDF: Anterior cervical discectomy and fusion, CDA: Cervical disc arthroplasty 
Table 4. Comparison of the presence of postoperative dysphonia and postoperative Odom Criteria among study groups

\begin{tabular}{|c|c|c|c|c|c|c|}
\hline & & \multicolumn{2}{|c|}{ ACDF $(n=32)$} & \multicolumn{2}{|c|}{$\operatorname{CDA}(n=39)$} & \multirow[b]{2}{*}{$\mathbf{p}^{*}$} \\
\hline & & $n$ & $\%$ & $\mathrm{n}$ & $\%$ & \\
\hline \multirow{2}{*}{ Postoperative dysphonia } & Absent & 31 & 96.9 & 39 & 100.0 & 0.451 \\
\hline & Present & 1 & 3.1 & 0 & 0.0 & \\
\hline \multirow{4}{*}{ Postoperative Odom Criteria } & Poor & 1 & 3.1 & 0 & 0.0 & 0.002 \\
\hline & Fair & 7 & 21.9 & 0 & 0.0 & \\
\hline & Good & 15 & 46.9 & 18 & 46.2 & \\
\hline & Excellent & 9 & 28.1 & 21 & 53.8 & \\
\hline
\end{tabular}

Table 5. Comparison of the time to return work among the study groups

\begin{tabular}{lllll}
\hline & & ACDF $(n=32)$ & CDA $(n=39)$ & $p^{*}$ \\
\hline \multirow{2}{*}{ Time to return work (day) } & Mean \pm SD & $15.7 \pm 3.5$ & $21.0 \pm 7.7$ & 0.004 \\
\cline { 2 - 4 } & Median (IQR) & $15.0(14.0-17.5)$ & $20.0(15.0-27.0)$ \\
\hline *Mann-Whitney U test was used. & & \\
ACDF: Anterior cervical discectomy and fusion, CDA: Cervical disc arthroplasty, SD: Standard deviation, IQR: Interquartile range
\end{tabular}

natural course of MC starts as type 1 and progresses towards type 3 . In this respect, although it resembles a chronic active inflammation, its cause is not fully explained. Although some studies have suggested that inflammation may be caused by anaerobic infection ${ }^{(25)}$, this hypothesis has been rejected in other studies ${ }^{(26)}$. This has led to the view that CDA, used as a segmental motion-preserving method, cannot prevent MC only by preserving segmental motion, and $\mathrm{MC}$ must have their own internal dynamics.

Our study has several limitations. First, we had a small number of patients. Second, the follow-up time was short to evaluate the long-term effects of the two methods. To address these limitations, randomized controlled studies with higher patient numbers and long-term follow-up are needed. Both surgical techniques were applied by two different surgeons and different centers, so which might have an effect of surgeon binded bias. This bias resolved by the third blinded surgeon who evaluated statistical results.

\section{CONCLUSION}

We found that standard ACDF and CDA treatments of cervical disc disease causing radiculopathy and myelopathy reached postoperative pain goals. However, we believe that MC have unique internal dynamics rather than an effect of the surgical technique. the comparison of clinically important secondary outcomes of CDA versus ACDF at two different centers in short to mid-term follow-up also showed beneficial results.

\section{Ethics}

Ethics Committee Approval: Ethical approval was obtained from Akdeniz University Faculty of Medicine Clinical Research Ethic Committee (approval no: KAEK-718, date: 13.10.2021).

Informed Consent: Retrospective study.
Peer-review: Externally peer-reviewed.

\section{Authorship Contributions}

Concept: N.Ü., Design: A.G, Data Collection or Processing: E.G., Analysis or Interpretation: N.Ü., Literature Search: NU., E.G., A.G., Writing: N.Ü., A.G., H.Ç.

Financial Disclosure: The authors declared that this study received no financial support.

Conflict of Interest: The authors have no conflicts of interest to declare.

\section{REFERENCES}

1. Tracey RW, Kang DG, Cody JP, Wagner SC, Rosner MK, Lehman RA Jr. Outcomes of single-level cervical disc arthroplasty versus anterior cervical discectomy and fusion. J Clin Neurosci. 2014;21:1905-8.

2. Hilibrand AS, Carlson GD, Palumbo MA, Jones PK, Bohlman HH. Radiculopathy and myelopathy at segments adjacent to the site of a previous anterior cervical arthrodesis. J Bone Joint Surg Am. 1999;81:519-28.

3. Hilibrand AS, Robbins M. Adjacent segment degeneration and adjacent segment disease: the consequences of spinal fusion? Spine J. 2004;4:190S-194S.

4. Whitecloud TS 3rd. Anterior surgery for cervical spondylotic myelopathy. Smith-Robinson, Cloward, and vertebrectomy. Spine (Phila Pa 1976). 1988;13:861-3.

5. Hisey MS, Zigler JE, Jackson R, Nunley PD, Bae HW, Kim KD, et al. Prospective, Randomized Comparison of One-level Mobi-C Cervical Total Disc Replacement vs. Anterior Cervical Discectomy and Fusion: Results at 5-year Follow-up. Int J Spine Surg. 2016;10:10.

6. McAfee PC, Reah C, Gilder K, Eisermann L, Cunningham B. A metaanalysis of comparative outcomes following cervical arthroplasty or anterior cervical fusion: results from 4 prospective multicenter randomized clinical trials and up to 1226 patients. Spine (Phila Pa 1976). 2012;37:943-52.

7. Odom GL, Finney W, Woodhall B. Cervical disk lesions. J Am Med Assoc. 1958;166:23-8. 
turkishspine

8. Gwinn DE, lannotti CA, Benzel EC, Steinmetz MP. Effective lordosis: analysis of sagittal spinal canal alignment in cervical spondylotic myelopathy. J Neurosurg Spine. 2009;11:667-72.

9. Barsa P, Suchomel P. Factors affecting sagittal malalignment due to cage subsidence in standalone cage assisted anterior cervical fusion. Eur Spine J. 2007;16:1395-400.

10. Hacker RJ. A randomized prospective study of an anterior cervical interbody fusion device with a minimum of 2 years of follow-up results. J Neurosurg. 2000;93:222-6.

11. Hacker RJ, Cauthen JC, Gilbert TJ, Griffith SL. A prospective randomized multicenter clinical evaluation of an anterior cervical fusion cage. Spine (Phila Pa 1976). 2000;25:2646-54; discussion 2655.

12. Fountas KN, Kapsalaki EZ, Nikolakakos LG, Smisson HF, Johnston KW, Grigorian AA, et al. Anterior cervical discectomy and fusion associated complications. Spine (Phila Pa 1976). 2007;32:2310-7.

13. Riley LH 3rd, Skolasky RL, Albert TJ, Vaccaro AR, Heller JG. Dysphagia after anterior cervical decompression and fusion: prevalence and risk factors from a longitudinal cohort study. Spine (Phila Pa 1976). 2005; 30:2564-9.

14. Karabag H, Cakmak E, Celik B, Iplikcioglu AC, Soran AF. Arthroplasty versus fusion for single-level cervical disc disease. J Pak Med Assoc. 2014;64:1348-51.

15. Nabhan A, Steudel WI, Pape D, Ishak B. Segmental kinematics and adjacent level degeneration following disc replacement versus fusion: RCT with three years of follow-up. J Long Term Eff Med Implants 2007; 17:229-36.

16. Jiang H, Zhu Z, Qiu Y, Qian B, Qiu X, Ji M. Cervical disc arthroplasty versus fusion for single-level symptomatic cervical disc disease: a meta-analysis of randomized controlled trials. Arch Orthop Trauma Surg 2012;132:141-51.

17. Peterson CK, Humphreys BK, Pringle TC. Prevalence of modic degenerative marrow changes in the cervical spine. J Manipulative Physiol Ther 2007;30:5-10.
18. Heller JG, Sasso RC, Papadopoulos SM, Anderson PA, Fessler RG, Hacker RJ, et al. Comparison of BRYAN cervical disc arthroplasty with anterior cervical decompression and fusion: clinical and radiographic results of a randomized, controlled, clinical trial. Spine (Phila Pa 1976). 2009;34:101-7.

19. An Y, Li J, Li Y, Shen Y. Characteristics of Modic changes in cervical kyphosis and their association with axial neck pain. J Pain Res. 2017;10:1657-61.

20. Sasso RC, Anderson PA, Riew KD, Heller JG. Results of cervical arthroplasty compared with anterior discectomy and fusion: fouryear clinical outcomes in a prospective, randomized controlled trial. J Bone Joint Surg Am, 2011;93:1684-92.

21. Peterson CK, Humphreys BK, Pringle TC. Prevalence of modic degenerative marrow changes in the cervical spine. J Manip Physiol Ther. 2007;30:5-10.

22. Gao X, Li J, Shi Y, Li S, Shen Y. Asymmetrical degenerative marrow (Modic) changes in cervical spine: prevalence, correlative factors, and surgical outcomes. J Orthop Surg Res. 2018;13:85.

23. Matsumoto $M$, Okada E, Ichihara D, Chiba K, Toyama $Y$, Fujiwara $\mathrm{H}$, et al. Modic changes in the cervical spine: prospective 10-year follow-up study in asymptomatic subjects. J Bone Joint Surg Br. 2012;94:678-83.

24. Zhang N, Li FC, Huang YJ, Teng C, Chen WS. Possible key role of immune system in Schmorl's nodes. Med Hypotheses. 2010;74:552-4.

25. Albert HB, Kjaer $P$, Jensen TS, Sorensen JS, Bendix T, Manniche $C$. Modic changes, possible causes and relation to low back pain. Med Hypotheses. 2008;70:361-8.

26. Wedderkopp N, Thomsen K, Manniche C, Kolmos HJ, Secher Jensen T, Leboeuf Yde C. No evidence for presence of bacteria in modic type I changes. Acta Radiol. 2009;50:65-70. 